\title{
Degradation Rate for Surface Pitting in GaN HEMT
}

\author{
Bruce M. Paine, Vincent T. Ng, Steve R. Polmanter, Neil T. Kubota, and Carl R. Ignacio \\ Technology Qualification \\ Boeing Network and Space Systems \\ El Segundo CA, USA \\ bruce.paine@boeing.com
}

\begin{abstract}
We developed nearly-independent electrical "signature parameters" for surface pitting, hot electron damage, and electron trapping in GaN HEMT RF power devices. We then used the surface pitting signature parameter to find the rate of this degradation mechanism, without influence from the other mechanisms, occurring concurrently. This is important so the extracted thermal activation energy for this common mechanism is correct, allowing accurate extrapolations to operating temperatures. We then utilized a new technique (described in detail elsewhere) to scale these measurements in DC lifetests, to normal RF operating conditions.
\end{abstract}

Keywords - failure analysis, gallium nitride, HEMTs, life testing, semiconductor device reliability.

\section{INTRODUCTION}

Surface pitting has been reported to be a major symptom of wearout in GaN HEMT devices $[1,2]$. But it is not the only symptom - other symptoms that suggest other mechanisms are reported widely: threshold voltage $\left(\mathrm{V}_{\text {th }}\right)$ shifts suggest electron trapping, eg. [3, 4], sudden gate leakage increases suggest "reverse piezoelectric" effects, eg. $[5,6]$, and drops in several parameters suggest hot electron damage, e.g. [3, 4]. Therefore, even though surface pitting may ultimately define the reliability of GaN HEMTs, it is important to separate its effects from the mechanisms that are proceeding concurrently. Otherwise the measurement of acceleration factors under RF stress will be compromised, making the predicted mean times to failure (MTTF's) inaccurate. We are not aware of any other quantitative studies that have separated the contributions of the various concurrent mechanisms.

Since the atomic mechanisms of wearout in a GaN HEMT device are likely to be quite complex, and dependent on many influences, we do not attempt to describe them in detail. Rather we identify them by their end results, as observed by many researchers: surface pits, trapped charge under or adjacent to the gate contact for "electron trapping", and trapping in the gate-drain region for "hot electron effects".

The key to our approach is finding a DC "signature parameter" for each mechanism, i.e. a parameter that scales with the magnitude of the degradation caused by this mechanism alone. This task is the main subject of the present paper. It involves the study of step-stress tests, DC lifetests, and RF lifetests, as well as some other tests that were specific to particular mechanisms.

The remainder of our approach is described in detail in [7]; we present it only briefly here. The next step is to find the thermal activation energy of each signature parameter, by

This work was supported by a Technology Investigation Agreement between Boeing and the Air Force Research Laboratory, contract \# FA865011-2-1187 (Lois Kehias), and a Boeing Network and Space Systems Internal Research and Development program (Remy Hiramoto). means of DC lifetests in the bias zone where that mechanism is expected to be strong. Then RF lifetests are conducted with normal biases and RF powers, and acceleration with temperature. Then the "scaling factors", i.e. degradation rate in the DC lifetests divided by degration rate under normal RF operation, can be calculated, all at a given temperature. Finally the MTTF's in the DC lifetests can be scaled to the expected MTTF's under normal RF operation.

Note, we do not assume that the mechanisms themselves are independent: indeed under RF operation, when many different bias zones are traversed, it is likely that one mechanism may "catalyze" another. For example, surface pitting or hot electrons may create more sites where electron trapping can occur. But once a signature parameter has been established convincingly, we do take it to be a measure of the degradation by that particular end result (eg. pits or trapped charges), no matter how much it may have been enhanced by other phenomena. And we assume that any "catalysis" by other mechanisms does not change the temperature dependence of that mechanism. For example, surface pitting or hot electron damage may offer more sites for traps, but we expect the thermal diffusion of charges into those sites is the same. The acceleration due to the larger number of sites, as well as any voltage acceleration, are measured with the scaling factor.

This, and several other assumptions and approximations are described in detail, and associated uncertainties are estimated [8]. The net overall uncertainties are relatively large: - $35 \%$, + $100 \%$ in MTTF. But this is adequate for a high-reliability parts evaluation, where a margin of at least $10 \mathrm{x} \quad(900 \%)$ is required. And it is a big improvement over the previous situation where individual degradation rates of multiple mechanisms during RF drive were unknown, except for special cases where all but one of them could be ignored.

\section{PARTS, EQUIPMENT AND GENERAL PROCEDURES}

Our overall technique was developed during study of several GaN HEMT technologies, with notably different structures; examples shown here are from a v-band power MMIC technology fabricated with MBE Ga-face material grown on (0001)-oriented Si-face $\mathrm{SiC}$ substrates. Wafer fabrication was done in 2011. There was no gate recess etch, and ohmic layers were grown selectively by MBE. The gates had 0.15 um footprint and were mushroom-shaped, with no field plates. Discrete transistors, with $150 \mu \mathrm{m}$ gate width were used for DC-only lifetesting, and the same transistors, in single-stage power MMICs were used for RF-stress lifetesting. Burn-ins were conducted with standard biasing, at $250{ }^{\circ} \mathrm{C}$ for $240 \mathrm{hrs}$, before beginning experiments. 
Devices from this process exhibited symptoms of surface pitting, electron trapping and hot electron effects. But we were unable to observe symptoms of the "reverse piezoelectric" mechanism [5, 6, 9] under $\mathrm{RF}$ operation. Therefore our technique does not work for this mechanism in this technology; rather an analogous approach will be needed, which scales the high DC electric fields and long durations that are reported to be necessary to see this phenomenon, to the much lower biases and shorter time intervals present in RF operation.

DC lifetesting was conducted on a commercial system using 30 of its 60 channels, on which full suites of static DC characterizations were conducted with an HP4142 DC source/monitor, under program control and with automatic switching. RF lifetests were conducted on a Boeing-built 10channel v-band system, with manual DC characterization by means of an Agilent B1500 Semiconductor Parameter Analyzer, and manual RF characterization with standard components. Fast-pulsed characterizations were conducted with an Auriga Microwave system, Model 4750.

Since slow traps make highly-stable DC characterizations of GaN HEMTs impossible, treatments were developed to put the traps in reproducible configurations before DC tests were begun [10]. These were called "traps full" (a bias sweep to high $\mathrm{V}_{\mathrm{dg}}$ ), and"traps empty" (bake at $150{ }^{\circ} \mathrm{C}$ for $30 \mathrm{~min}$ ). All tests were done with the base temperature set at $50{ }^{\circ} \mathrm{C}$. Temperatures where the degradation was occurring were calculated with a finite-difference code, which was calibrated against actual channel temperatures measured by two different techniques [11].

\section{SIGNATURE PARAMETERS}

A signature parameter is a DC parameter that tracks with one mechanism, alone. Our method for establishing the signature parameters was as follows:

A. Define the mechanism and propose a signature parameter. Since our goal is to quantify known mechanisms, and not shed further light on the atomic changes, we adopt definitions that are the most common in recent publications.

B. See how the parameter scales with stress duration and observed physical damage, if any. We execute the former by conducting DC lifetests in zones of the drain I-V plane where the individual mechanisms are expected to be strongest. This way, the electrical effects are the clearest.

C. See if it has any correlation with the other signature parameters, in stress tests.

D. See if it can be extracted from I-V curves, independently of the signatures of any other mechanisms.

E. Make a simple physical model for the mechanism and the signature parameter, and see if there are plausible physical arguments for linking the parameter to that mechanism, and no others.

\section{A. Mechanisms and Signature Parameters}

Surface pitting is loss of localized patches of surface semiconductor, immediately adjacent to the gate contact, on the drain side, together with possible extended defects beneath the pits. We observed this phenomenon consistently and

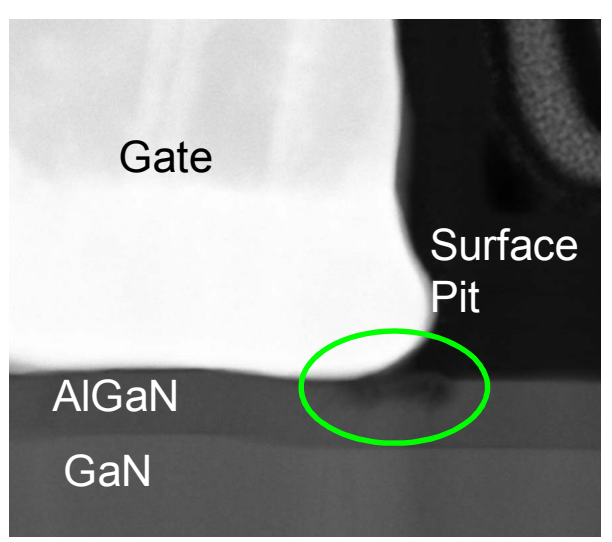

Fig. 1. FIB cross section of the gate contact (drain side) after DC lifetest at $\left(\mathrm{V}_{\mathrm{g}}, \mathrm{V}_{\mathrm{d}}, \mathrm{T}_{\mathrm{ch}}\right)=(-4,20,125)$, for $3,000 \mathrm{hrs}$.

clearly in all FIB cross-sections that were made on parts that had been subject to high- $\mathrm{V}_{\mathrm{dg}}$ stress: $\left(\mathrm{V}_{\mathrm{g}}, \mathrm{V}_{\mathrm{d}}\right)=(-4,20)$. An example is shown in Fig. $1 . \delta I_{\text {dmax }}$, defined as change in drain current with $\left(\mathrm{V}_{\mathrm{d}}, \mathrm{V}_{\mathrm{g}}\right)=(+5,+2)$, has been proposed to measure this phenomenon [2]. But at fixed $\mathrm{V}_{\mathrm{g}}$, this will be affected by changes in threshold voltage, $V_{\text {th }}$. Also, we want to keep it in the linear region of $I_{d} v s$. $V_{d}$, so it is independent of $\mathrm{G}_{\mathrm{m}}$. So we re-defined $\delta \mathrm{I}_{\mathrm{dmax}}$ to be at lower $\mathrm{V}_{\mathrm{d}}$, and at constant forward gate current instead: $\delta \mathrm{I}_{\mathrm{d} \max }=\delta \mathrm{I}_{\mathrm{d}}$ for $\left(\mathrm{V}_{\mathrm{d}}, \mathrm{I}_{\mathrm{g}}\right)=(+1$, $6.7 \mathrm{~mA} / \mathrm{mm}$ ).

Hot electrons cause generation of fixed charge embedded within layers (and passivation), distributed between gate and drain. It has been shown [3] that this results in monotonic reduction of the transconductance $\left(\mathrm{G}_{\mathrm{m}}\right)$ versus $\mathrm{V}_{\mathrm{g}}$. We chose to use the change in the peak of this curve $\left(\delta \mathrm{G}_{\mathrm{mp}}\right)$, in an effort to gauge the effect, independent of threshold shifts, or the precise location of the damage, relative to gate and drain. This was measured at $\mathrm{V}_{\mathrm{d}}=10 \mathrm{~V}$ in our example.

Electron trapping close to the gate results in modification of the depletion region immediately beneath the gate. This is commonly measured as shifts in the threshold voltage, $\delta \mathrm{V}_{\text {th }}$, without corresponding change in the gate turn-on voltage $\delta$ $\mathrm{V}_{\text {gon }}$ (see for example [12]). We defined $\mathrm{V}_{\text {th }}$ as $\mathrm{V}_{\text {peak }}-$ $I_{\text {peak }} / G_{m p}$, where $V_{\text {peak }}$ and $I_{\text {peak }}$ are the $V_{g}$ and $I_{d}$ corresponding the peak in $G_{m}$.

TABLE I. SignATURE PARAMETERS (ADOPTED AFTER STUDIES BELOW)

\begin{tabular}{|c|c|c|}
\hline Mechanism & Para. & Description \\
\hline Surface Pitting & $\delta I_{\mathrm{dmax}}$ & $\delta \mathrm{I}_{\mathrm{d}}$ for $\left(\mathrm{V}_{\mathrm{d}}, \mathrm{I}_{\mathrm{g}}\right)=(+1 \mathrm{~V}, 6.7 \mathrm{~mA} / \mathrm{mm})$ \\
\hline Hot Electrons & $\delta \mathrm{G}_{\mathrm{mp}}$ & Peak of $G_{m}$ vs. $V_{g}$ curve, $V_{d}=10 \mathrm{~V}$ \\
\hline $\begin{array}{l}\text { Electron } \\
\text { Trapping }\end{array}$ & $\delta \mathrm{V}_{\text {th }}$ & $\begin{array}{l}V_{\text {peak }}-\mathrm{I}_{\text {peak }} / \mathrm{G}_{\mathrm{mp}} ; \text { peaks in } \mathrm{G}_{\mathrm{m}} \text { vs. } \\
\mathrm{V}_{\mathrm{g}} \text { curve }\end{array}$ \\
\hline
\end{tabular}




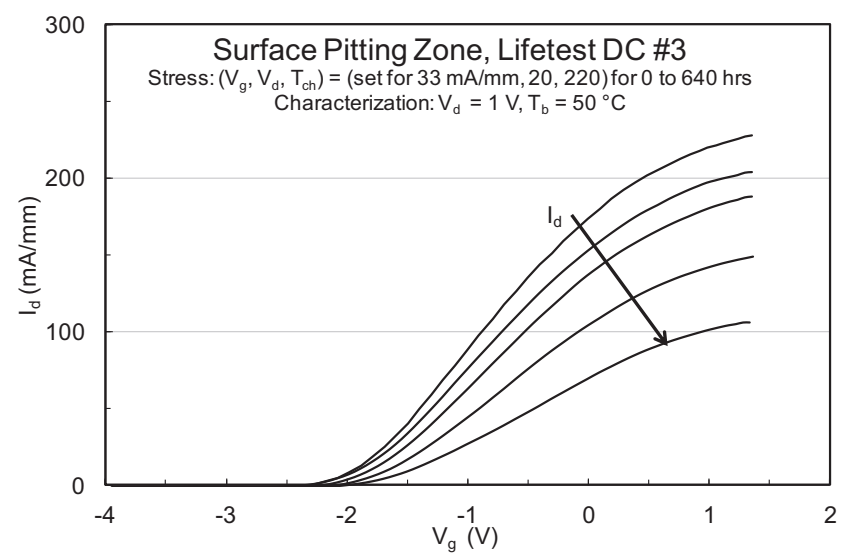

Fig. 2. Example of the evolution of $\mathrm{I}_{\mathrm{d}}-\mathrm{V}_{\mathrm{g}}$ curves during lifetest in the surface pitting zone. $\mathrm{I}_{\mathrm{dmax}}$ is read at $\mathrm{I}_{\mathrm{g}}=6.7 \mathrm{~mA} / \mathrm{mm}$ (data not shown), which occurs near $\mathrm{V}_{\mathrm{g}}=+1.0 \mathrm{~V}$.

\section{B. Comparison with Stress Duration and Observed Physical Damage}

The surface pitting zone was chosen to be $\left(\mathrm{V}_{\mathrm{d}}, \mathrm{I}_{\mathrm{d}}\right)=(20,33$ $\mathrm{mA} / \mathrm{mm}$ ). Typical progression of $I_{\mathrm{dmax}}$ with stress time is illustrated in Figure 2. It clearly declined strongly with stress. Meanwhile, $\mathrm{V}_{\text {th }}$ increased. But $\mathrm{G}_{\mathrm{mp}}$ degraded less than $10 \%$, which is consistent with the fact that with $I_{d}$ only $33 \mathrm{~mA} / \mathrm{mm}$ the hot electron current was very small.

It has been shown quantitatively that $I_{\text {dmax }}$ scales approximately linearly with the amount of surface pitting damage, seen in cross sections [13]. So this supports the choice of $\delta \mathrm{I}_{\mathrm{dmax}}$.

Meanwhile, we found the hot electron zone by measuring electroluminescense per unit drain current, in multiple sweeps across the drain I-V plane. Temperature dependence was also measured, and the results scaled to a fixed channel temperature. Thus for $\mathrm{V}_{\mathrm{d}}=12 \mathrm{~V}$, the hot electron zone was found to be at $\left(\mathrm{V}_{\mathrm{d}}, \mathrm{I}_{\mathrm{d}}\right)=(12,267 \mathrm{~mA} / \mathrm{mm})$. A sequence of $\mathrm{G}_{\mathrm{m}}$ curves for stress at this condition is shown in Fig. 3. Clearly the peak $\mathrm{G}_{\mathrm{m}}$ dropped strongly with stress, making it a good candidate to track the hot electron effects, in spite of the fact that $\mathrm{V}_{\text {th }}$ obviously increased strongly at the same time.

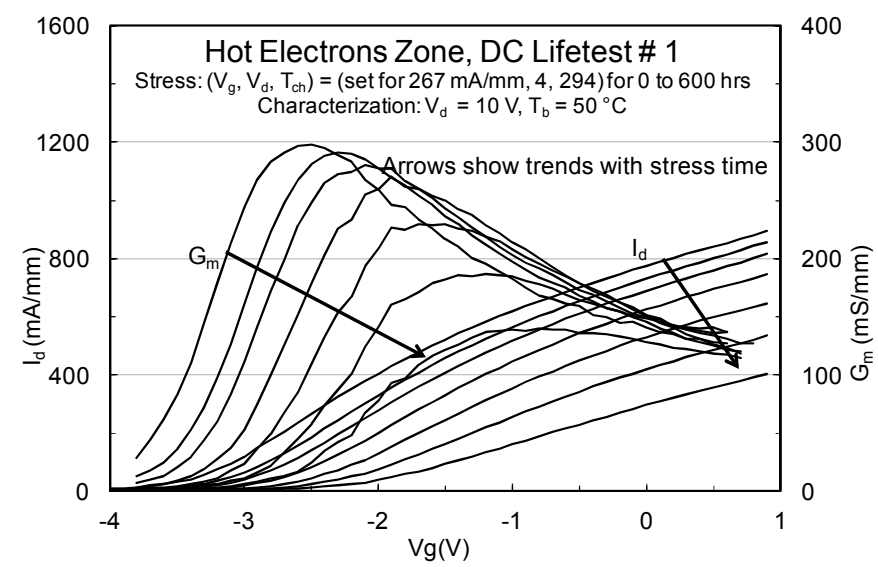

Fig. 3. Example of the evolution of $\mathrm{G}_{\mathrm{m}}$ and $\mathrm{I}_{\mathrm{d}}$ curves during lifetest in the hot electrons zone. $\mathrm{G}_{\mathrm{mp}}$ values are read at the maxima of the $\mathrm{G}_{\mathrm{m}}$ curves.
Standard SEM and STEM imaging of FIB cross sections through parts stressed in the hot electron and electron trapping zones showed no significant changes. Therefore, we were not able to compare $\delta \mathrm{G}_{\mathrm{mp}}$ and $\delta \mathrm{V}_{\text {th }}$ with observable damage levels. The electron trapping zone was chosen to be $\left(\mathrm{V}_{\mathrm{g}}, \mathrm{V}_{\mathrm{d}}\right)=$ $(-4,10)$, and a progression of curves during stress is shown in Figure 4 . We see that in the first 3 intervals, $G_{m p}$ drops only 5 $\%$ while $\mathrm{V}_{\text {th }}$ increases by $470 \mathrm{mV}$. So $\mathrm{V}_{\text {th }}$ appears to be tracking the electron trapping and $\mathrm{G}_{\mathrm{mp}}$ reflects the small amount of hot electrons also present $\left(\mathrm{I}_{\mathrm{d}} \sim 33 \mathrm{~mA} / \mathrm{mm}\right.$ during the stress).

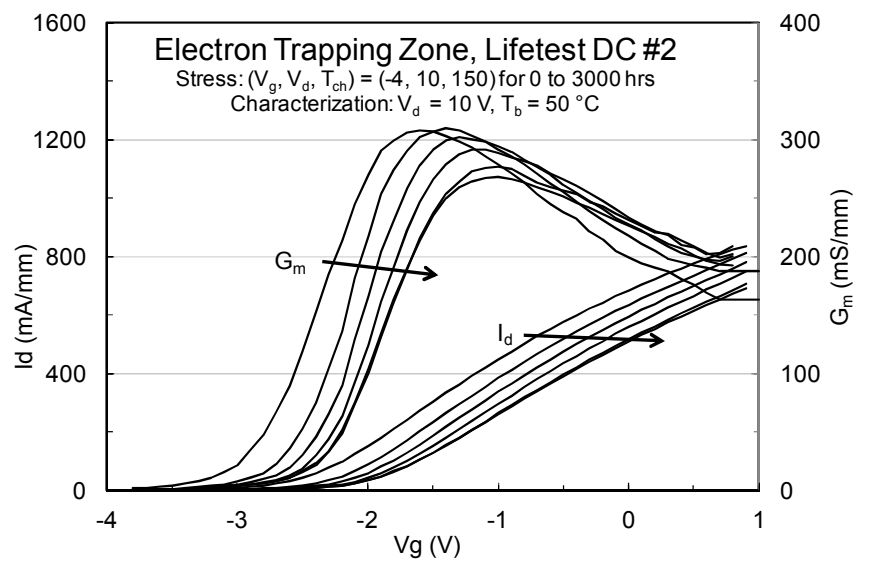

Fig. 4. Example of the evolution of $G_{m}$ and $I_{d}$ curves during lifetest in the electron trapping zone. $V_{\text {th }}$ is read at the intersection of the $I_{d}$ curve, extrapolated linearly from the inflection point, to $I_{d}=0$.

\section{Checks for Correlations}

For the signature parameters to be valid, they must remain independent of each other when all 3 mechanisms are active simultaneously. This is best checked with RF stress, since the biases will pass through all the relevant zones. Therefore, we conducted an RF stress test with stepped $T_{\text {ch }}$, which is illustrated in Fig. 5. At the beginning, $\left(\mathrm{V}_{\mathrm{d}}, \mathrm{I}_{\mathrm{d}}, \mathrm{T}_{\mathrm{ch}}\right)=(12 \mathrm{~V}, 276$

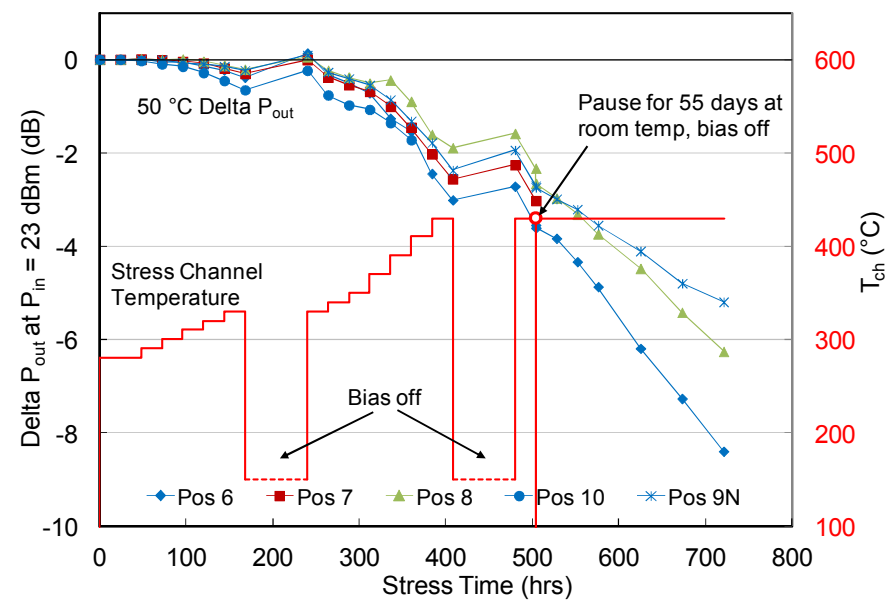

Fig. 5. RF stress test on a 1-stage amplifier, with stepped channel temperature $\left(T_{c h}\right)$. Changes in the compressed output power are plotted for 5 specimens. 


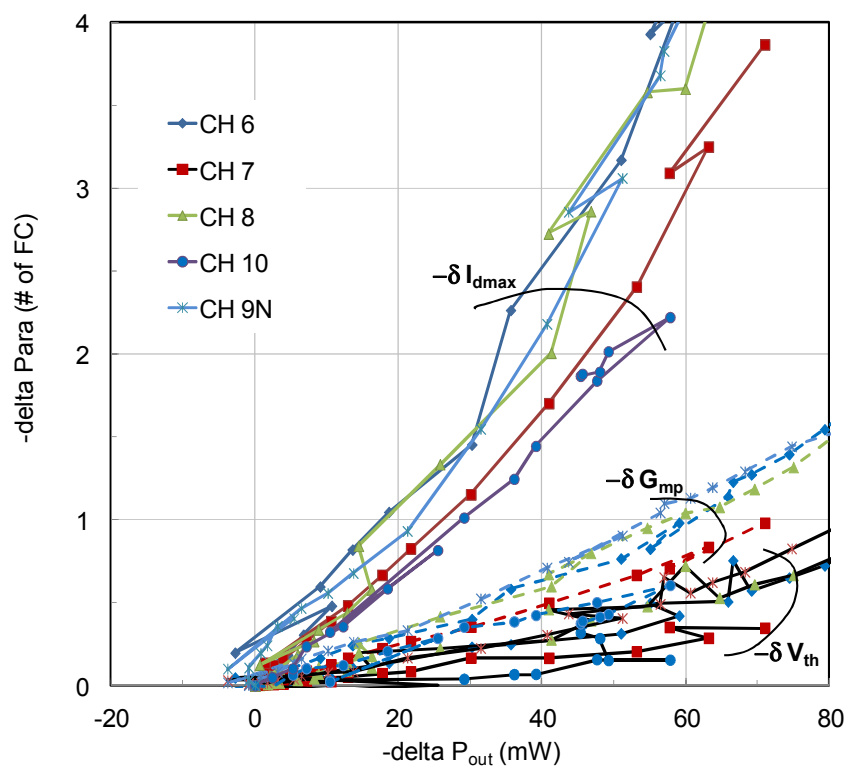

Fig. 6. Some analysis of the RF step-stress outlined in Fig. 5. The delta's in $\mathrm{I}_{\mathrm{dmax}}, \mathrm{G}_{\mathrm{mp}}$ and $\mathrm{V}_{\text {th }}$ are plotted against the delta's in RF output power, all measured at $50{ }^{\circ} \mathrm{C}$, after each 24 -hr stress. To get an idea of the absolute effects of these changes, the delta in each parameter is normalized to the estimated delta needed to induce $1 \mathrm{~dB}$ drop in $\mathrm{P}_{\text {out }}$, ie. "number of failure criteria".

$\mathrm{mA} / \mathrm{mm}, 280{ }^{\circ} \mathrm{C}$ ), with constant input RF power at $62 \mathrm{GHz}$, sufficient for at least $5 \mathrm{~dB}$ gain compression at $50{ }^{\circ} \mathrm{C}$. After 24 hrs the stress was removed and DC and RF characterizations conducted during the next $24 \mathrm{hrs}$. Then $\mathrm{T}_{\text {ch }}$ was increased and another $24 \mathrm{hrs}$ of stress applied. This cycle was continued to $430{ }^{\circ} \mathrm{C}$, after which the temperature was held constant. Also, there were two periods of "bias-off" at $150{ }^{\circ} \mathrm{C}$, and one with "bias-off" at room temperature.

We plotted the changes in $I_{d \max }$, as well as $G_{m p}$ and $V_{\text {th }}$ versus change in $\mathrm{P}_{\text {out }}$, in Fig. 6 . To compare the absolute effects in the plot, we normalized the delta in each parameter to the estimated delta in that parameter needed to produce a $1 \mathrm{~dB}$ reduction of $\mathrm{P}_{\text {out }}$ (i.e approximately -20 to $-30 \mathrm{~mW}$ ). The latter was estimated from modelling described elsewhere [7]. This is labelled "\# of FC", ie. "number of failure criteria".

We see that $\delta \mathrm{I}_{\mathrm{dmax}}$ correlates well with $\delta \mathrm{P}_{\text {out }}$, and accounts for a large portion of the change. Even when there was some recovery of $\mathrm{P}_{\text {out }}$ during the bias-off's (perhaps from annealing of some disorder at the edges of the pits), $\delta \mathrm{I}_{\mathrm{dmax}}$ recovered almost linearly with $\delta \mathrm{P}_{\text {out }}$. By contrast, when the bias-off's occurred $\delta \mathrm{V}_{\text {th }}$ stayed constant or increased. However there is good correlation with $\delta \mathrm{G}_{\mathrm{mp}}$, suggesting the hot electron damage also anneals during the bakes. But the $\delta \mathrm{G}_{\mathrm{mp}}$ is too small in magnitude to explain $\delta \mathrm{P}_{\text {out }}$. Similarly, MIT reported that $I_{d m a x}$ scales near-linearly with RF output power, $P_{\text {out }}$ [14] when other mechanisms were minimized.

We also looked at the correlation of these 3 parameters during burn-ins. We found that normalized $\delta \mathrm{V}_{\text {th }}$ increased by 0.5 to $1.0 \mathrm{~V}$ during burn-in, while $\mathrm{I}_{\mathrm{dmax}}$ shifted up or down by $<$ $10 \%$, and $\mathrm{G}_{\mathrm{mp}}$ dropped by only 10 to $20 \%$. From all of these empirical observations, we conclude that $\delta \mathrm{I}_{\mathrm{dmax}}, \delta \mathrm{G}_{\mathrm{mp}}$ and $\delta$
$\mathrm{V}_{\text {th }}$, as defined here, are nearly independent of each other, for this GaN HEMT technology.

\section{Extraction from I-V Curves}

Another element in checking for independence of the proposed signature parameters is determining whether they can be extracted from I-V curves, independently of other parameters. This is shown to be true in Fig. 7: if $\mathrm{V}_{\text {th }}$ degrades, $I_{d}$ and $G_{m}$ curves shift to different $V_{g}$ 's, but the magnitude of $\mathrm{G}_{\mathrm{mp}}$ stays the same. Conversely, If $\mathrm{G}_{\mathrm{mp}}$ degrades, the $\mathrm{I}_{\mathrm{d}}$ and $\mathrm{G}_{\mathrm{mp}}$ curves are reduced, but their positions stay the same, so $V_{\text {th }}$ stays the same.

Extraction of $I_{d m a x}$, independent of $G_{m p}$ and $V_{t h}$ is illustrated in Fig. 8: $\delta \mathrm{G}_{\mathrm{mp}}$ and $\delta \mathrm{V}_{\text {th }}$ cause drops in saturated current. But $\delta \mathrm{I}_{\text {dmax }}$ is a drop in linear current, due to $\mathrm{R}_{\text {on }}$ increase (corrected for $\mathrm{V}_{\text {th }}$ shifts). These effects are nearly independent.
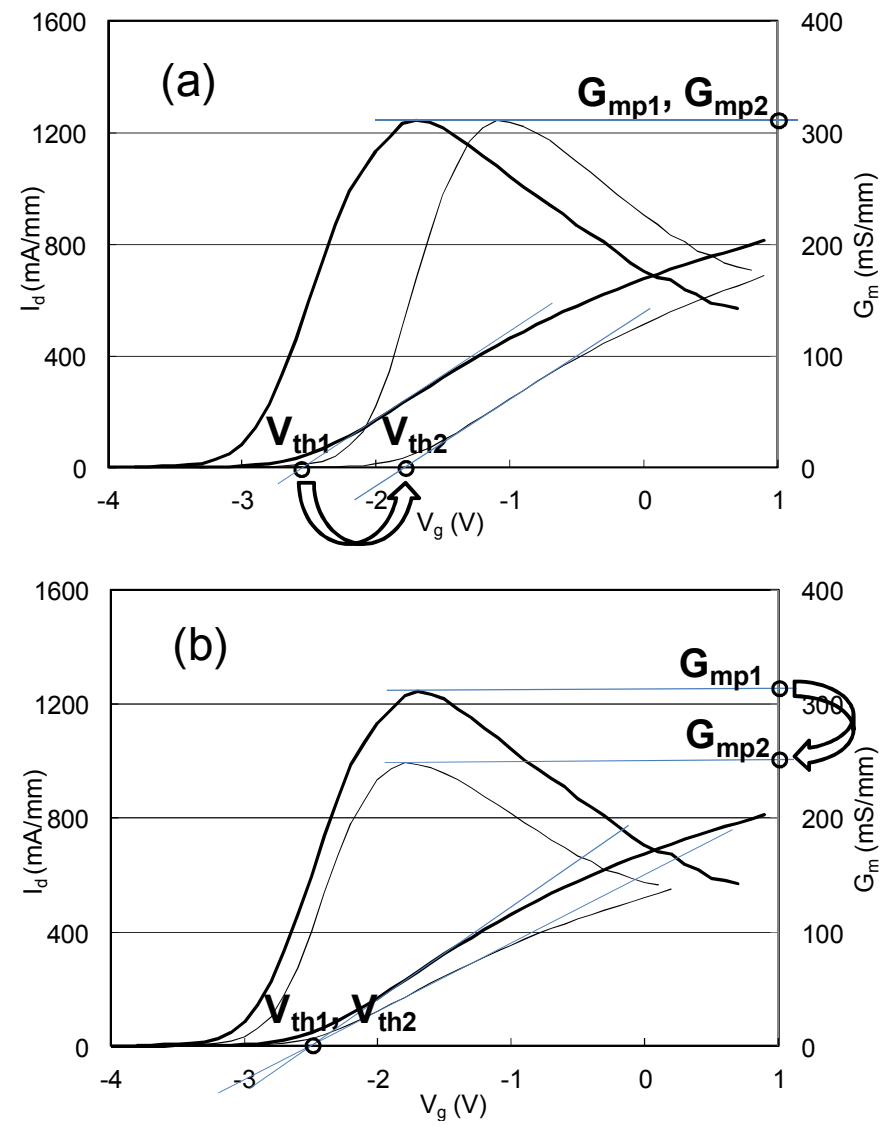

Fig. 7. Illustration of the independence of $\delta \mathrm{G}_{\mathrm{mp}}$ and $\delta \mathrm{V}_{\mathrm{th}}$ in I-V curves. (a) was recorded in the electron trapping zone, where $\mathrm{V}_{\text {th }}$ showed large changes without affecting $\mathrm{G}_{\mathrm{mp}}$. Conversely, (b) was recorded in the hot electron zone, where $\mathrm{G}_{\mathrm{mp}}$ dropped substantially without affecting $\mathrm{V}_{\text {th }}$. 


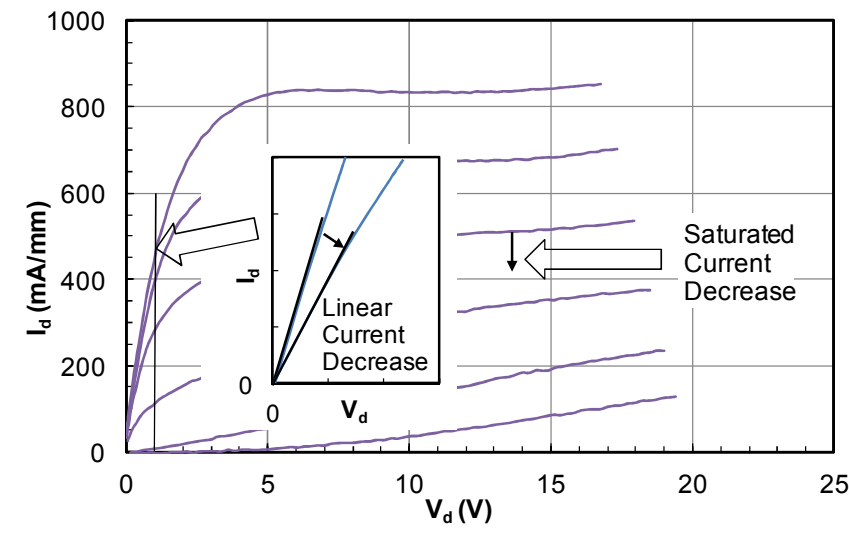

Fig. 8. Illustration of the independence of $\delta \mathrm{I}_{\mathrm{dmax}}$ from $\delta \mathrm{G}_{\mathrm{mp}}$ and $\delta \mathrm{V}_{\text {th }}$. Reduction of $\mathrm{G}_{\mathrm{mp}}$ or increase of $\mathrm{V}_{\text {th }}$ reduce the saturated current. But increase of $R_{\text {on }}$ reduces $I_{d m a x}$ almost independently of this.

\section{E. Physical Models}

The physical reason for the choice of $\mathrm{V}_{\text {th }}$ is straightforward. We found that for this technology, $V_{\text {gon }}$ (the gate bias for forward conduction of $0.1 \mathrm{~A} / \mathrm{mm}$ ) did not change significantly. Therefore, increase of $V_{\text {th }}$ (at a fixed $V_{d}$ ) leads to decrease of the currents at all $\mathrm{V}_{\mathrm{g}}$ 's, ie. reduced output power. And it is well known [e.g. 3, 4] that $\mathrm{V}_{\text {th }}$ changes occur from changes in trap populations adjacent to, or beneath the gates: biases from the trapped charges alter the depletion from the Schottky barrier.

We now consider the physical reasons for the choices of $\delta$ $\mathrm{I}_{\mathrm{dmax}}$ and $\delta \mathrm{G}_{\mathrm{mp}}$. Both surface pitting and hot electron damage have the effect of pinching off the channel, so it is a challenge to distinguish them with DC tests. But it appears to be possible during the early stages of degradation, thanks to the different physical locations of the damage. Surface pitting occurs only adjacent to the gate contact, mostly on the drain side, and begins as local regions which gradually spread and eventually coalesce into a continous trench [15]. So we imagine the initial effects as local patches of full depletion, which block current flow, and effectively reduce the width of the channel. (See Fig. 9.) This effect is best tracked by drain current when the unblocked parts of the gate are fully on, ie. $\mathrm{I}_{\mathrm{dmax}}$. (And we correct for $\mathrm{V}_{\text {th }}$ changes by measuring $\mathrm{I}_{\mathrm{dmax}}$ at the $\mathrm{V}_{\mathrm{g}}$ required to obtain a a fixed $\mathrm{I}_{\mathrm{g}}$.)

By contrast, hot electron damage is widely-spread, varying smoothly (on a tenth-micron scale) with distance between the gate and drain, and peaking at some point between them. So at the beginning, the hot electron depletion is small and increases gradually, across the full width of the channel. This has the effect of gradually masking the effect of the gate, and this effect is best monitored by the change in $I_{d}$ per unit change of $\mathrm{V}_{\mathrm{g}}$, ie. the transconductance. (And we correct for $\mathrm{V}_{\text {th }}$ changes this time by reading $G_{m}$ at the $V_{g}$ where $G_{m}$ peaks.) Of course the $\mathrm{G}_{\mathrm{mp}}$ changes have some effect on $\mathrm{I}_{\mathrm{dmax}}$, but we minimize them by measuring $\delta I_{d \max }$ at very low $V_{d}$ (just 1 volt), where $\mathrm{G}_{\mathrm{mp}}$ is very small, but $\mathrm{I}_{\mathrm{dmax}}$ is still substantial. Conversely, $\delta$ $\mathrm{G}_{\mathrm{mp}}$ is measured at high $\mathrm{V}_{\mathrm{d}}(10 \mathrm{~V}$ for this technology), where it is most sensitive to changes in the gate-drain region.

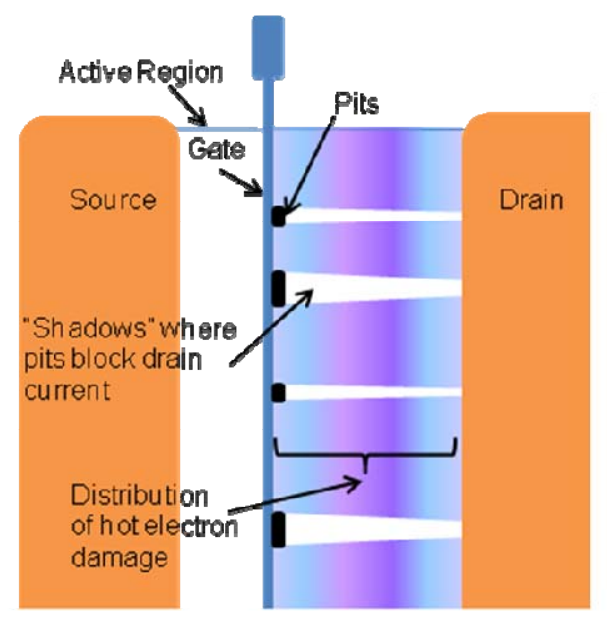

Fig. 9. Schematic diagram showing localized surface pits, contrasted with distributed damage from hot electrons, in regions that are not "shadowed" by the pits.

\section{F. Fast Pulsing}

We checked the effect of using fast-pulsed ( $\mu$ s) testing for these three parameters, for this GaN HEMT technology. We chose the quiescent point to represent normal RF operation, i.e. $\left(\mathrm{V}_{\mathrm{d}}, \mathrm{I}_{\mathrm{d}}, \mathrm{T}_{\mathrm{ch}}\right)=\left(12,250 \mathrm{~mA} / \mathrm{mm}, 50^{\circ} \mathrm{C}\right)$. We found the $\mathrm{I}_{\mathrm{dmax}}$ readings were $2 \mathrm{x}$ larger than those from static measurements, whereas $G_{m p}$ and $V_{\text {th }}$ readings were the same. We therefore concluded that some slow trap movements are compromising the static measurements of $I_{\text {dmax }}$, whereas static measurements are adequate for $\mathrm{V}_{\text {th }}$ and $\mathrm{G}_{\mathrm{mp}}$. Therefore we modified our lifetest system to routinely conduct IV tests with fast pulsing: we wired the pulsers through RF ports on our lifetest fixtures, and installed switches to remove the high-capacitance stabilization circuitry during pulsed measurements. This allowed us to make accurate in-situ pulsed characterizations with $\sim 1 \mu$ s resolution, with negligible physical disturbance of the specimens undergoing lifetest. An example of some measurements, as a single-stress lifetest progressed, was shown in Fig. 2.

\section{G. Alternative Signature Parameters}

"Current collapse" is sometimes used to monitor GaN degradation, for example in [14]. It is usually defined as the percentage difference between $I_{d}$ measurements with "traps full" (usually pulsing from a very high $\mathrm{V}_{\mathrm{gd}}$ condition) and "traps empty" (usually from a static measurement or pulsing from the zero-bias state). But these starting points do not represent conditions in a real operation: a device under RF operation never stays long enough near either state for most trap populations to react, and these states are far from any real load line. As a result, the "traps full" state probably fills many traps that are not filled in normal operation. As an example, if we take $\delta \mathrm{I}_{\mathrm{dmax}}$ to be equal to the current collapse measured in a recent RF lifetest in our laboratory (-45\%), then our FET model predicts $\delta \mathrm{P}_{\text {out }} \sim-4.2 \mathrm{~dB}$, whereas it was actually only $2.7 \mathrm{~dB}$. 
The on resistance $\left(R_{o n}\right)$ has been used by others to characterize surface pitting, e.g [14]. This is the resistance measured at $\left(\mathrm{V}_{\mathrm{d}}, \mathrm{V}_{\mathrm{g}}\right) \sim(0,+1)$. We looked at the correlation of this parameter with $\delta \mathrm{P}_{\text {out }}$, and found that $\mathrm{R}_{\text {on }}$ increases strongly super-linearly with $\delta \mathrm{P}_{\text {out }}$. We speculate this is because $\mathrm{R}_{\text {on }}$ is affected by two mechanisms simultaneously: the surface pitting makes the drain IV curves show higher resistance near the origin, and electron trapping effectively shifts $\mathrm{V}_{\mathrm{g}}=+1 \mathrm{~V}$ to a lower I-V curve. Therefore we conclude $\delta \mathrm{R}_{\text {on }}$ is not a good parameter for surface pitting.

\section{RESUlts FOr SURFACE PITTING}

The bias zone for the surface pitting lifetests was $\left(\mathrm{V}_{\mathrm{d}}, \mathrm{I}_{\mathrm{d}}\right)=$ $(20,33 \mathrm{~mA} / \mathrm{mm})$, and DC lifetests were conducted at channel temperatures $\left(\mathrm{T}_{\mathrm{ch}}\right)$ of 200 and $220{ }^{\circ} \mathrm{C}$. Meanwhile, an RF lifetest was conducted at $320{ }^{\circ} \mathrm{C}$. We found $\delta \mathrm{I}_{\text {dmax }}$ degraded

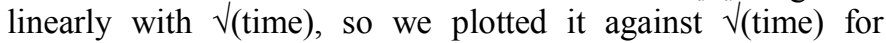
convenience during extraction of failure times (see Fig. 10).
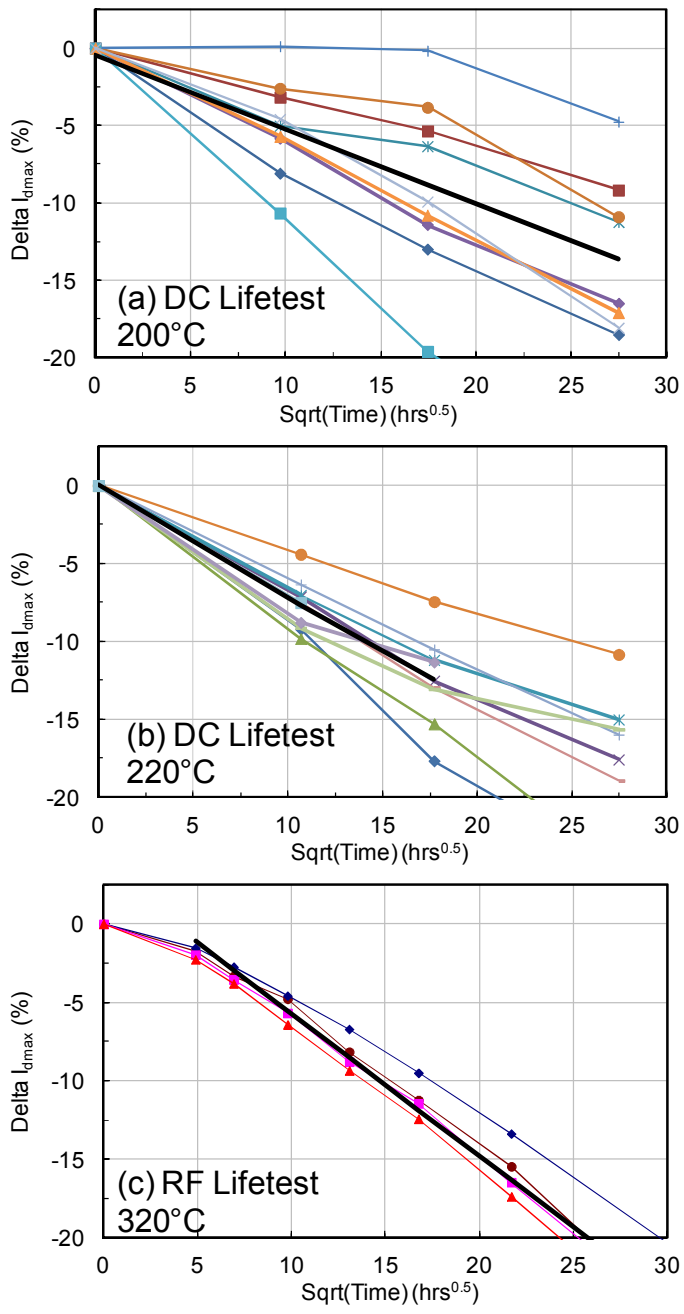

Fig. 10. Degradation of $I_{d m a x}$ in DC lifetests (a and b) and an RF lifetest (c). These are plotted against $\sqrt{ }($ time) for convenience during interpolation to find failure times. The heavy lines are averages of all the specimens. The nonlinearity of the data in the early hours of the RF lifetest is likely to be a "burnin" effect, which would be eliminated in early testing of a product, and was therefore ignored.
Analytical modeling [7] shows that the failure criterion corresponding to $\delta \mathrm{P}_{\text {out }}=-1 \mathrm{~dB}$ is $\delta \mathrm{I}_{\mathrm{dmax}}=-10 \%$. A log-normal plot for this criterion, from the DC lifetest, is shown in Fig. 11. We note that the standard deviations of the two curves are rather different (1.1 and 0.4 ). This is probably caused by the fact that the specimens for the $200{ }^{\circ} \mathrm{C}$ lifetest were taken from a substantially wider area of the wafer.

An Arrhenius analysis of the MTTF's from the DC lifetest is shown as the discrete symbols in Fig. 12 (a). It yields $\mathrm{E}_{\mathrm{a}}=$ $0.78 \pm 0.2 \mathrm{eV}$. Adjusting Fig. 10 (c) to the temperatures of the DC lifetests, we find the scaling factor is 26.1. This is applied to the Arrhenius data in Fig. 12 (a) to get the Arrhenius curve predicted for normal RF conditions.

Analogous lifetests and analysis were conducted for electron trapping and hot electron effects [7]. The results for all three mechanisms are plotted in Fig. 12 (b). (Note that the MTTF axis of Fig. 12 (b) is shifted by 100 relative to that of Fig. 12 (a) ). We can see that for channel temperatures above $80^{\circ} \mathrm{C}$ or so, surface pitting will probably cause failure first, while below $80{ }^{\circ} \mathrm{C}$, electron trapping will probably cause failure first. Only if the process is improved to reduce surface pitting (as has been done by some labs - see [16]), would hot electron effects possibly define the reliability, at high channel temperatures. We see that in $\mathrm{RF}$ operation with a channel temperature of $150{ }^{\circ} \mathrm{C},\left(\mathrm{T}_{\text {base }} \sim 50{ }^{\circ} \mathrm{C}\right)$, the MTTF for electron trapping is $1 \times 10^{5} \mathrm{hrs}$. We estimated the uncertainties of the MTTF's to be $-35 \% /+100 \%$ for the 220 to $350{ }^{\circ} \mathrm{C}$ interval spanned by lifetests, climbing gradually higher as temperatures depart from this range.

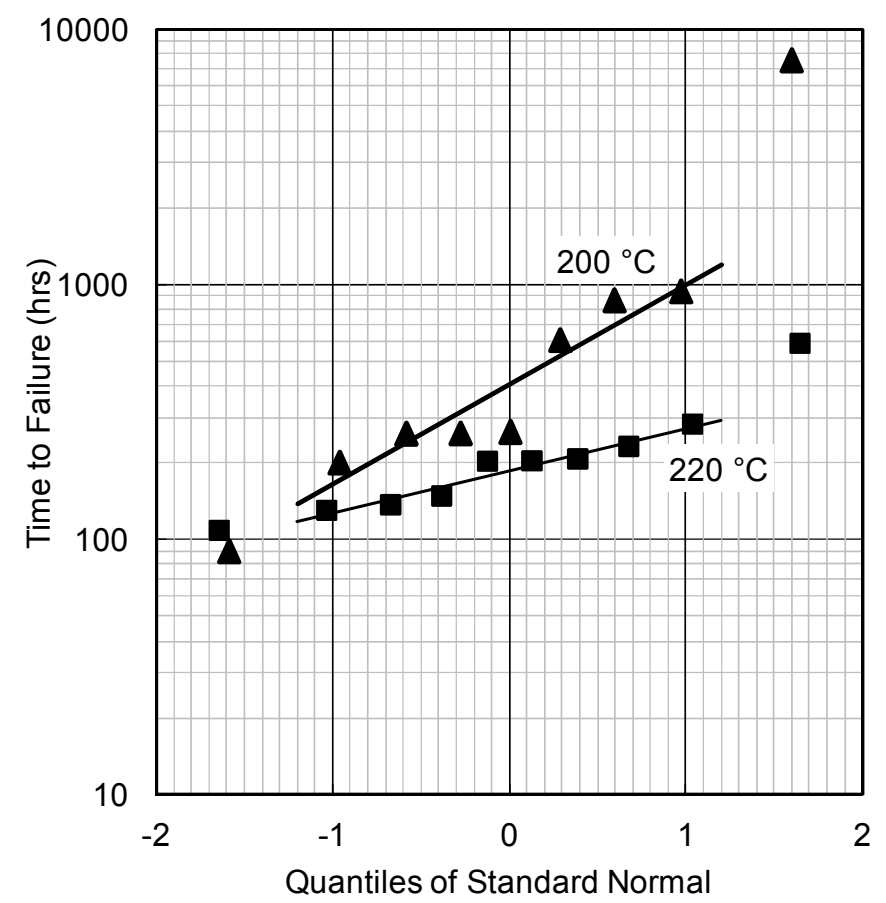

Fig. 11. Log-normal plot of failure times in the DC lifetest, for $\delta \mathrm{I}_{\mathrm{dmax}}=-10 \%$. The large scatter in the $200{ }^{\circ} \mathrm{C}$ data is likely caused by taking specimens from a wide area of the wafer. 

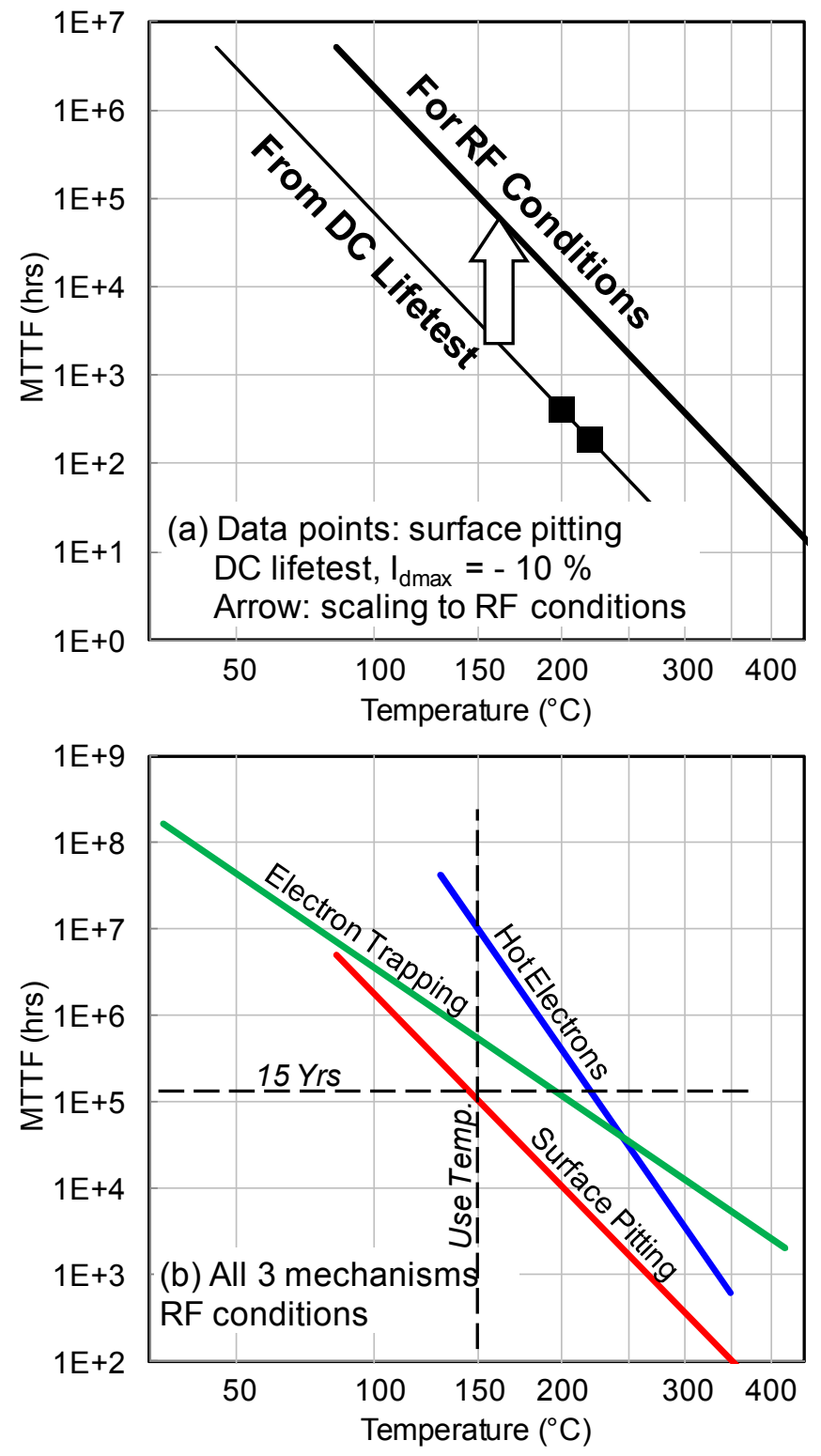

Fig. 12. Arrhenius plots of measured mean times to failure, versus channel temperature. The data points in part (a) are taken from the log-normal plot of Figure 11. These are shifted to normal RF operating conditions with a scaling factor, indicated by the large arrow. The scaling factor was found from the ratio of the degradation rate under DC operation to the degradation rate under RF operation, in the lifetests of Figure 10. Part (b) shows this result, together with the results of analogous lifetests for electron trapping and hot electrons.

\section{ACKNOWLEDGMENT}

Instrumentation and assembly support were provided by Bartley J. Price and Sang Nguyen of Boeing. Test support was provided by Larry R. Duncan. Valuable consultations were provided by Dr. Andy C. Chen, John R. Grebliunas and Dr. Stephen Thomas III of Boeing.

\section{REFERENCES}

[1] J. L. Jimenez and U. Chowdhury, "Recent advances on the understanding of the physics of failure of GaN on SiC FET technology", Workshop on Reliability of Compound Semiconductors, pp. $57-58$, 2009.

[2] J. Joh, J. A. del Alamo, K. Langworthy, S. Xie, T. Zheleva, "Correlation between electrical and material degradation in GaN HEMTs stressed around and beyond the critical voltage", Workshop on Reliability of Compound Semiconductors, pp. 103 - 107, 2010.

[3] E. Zanoni, G. Meneghesso, G. Verzellesi, F. Danesin, M. Meneghini, F. Rampazzo, A. Tazzoli, F. Zanon, "A Review of Failure Modes and Mechanisms of GaN-based HEMTs", Proc. of the IEEE International Electron Devices Meeting, pp. 381 -384, 2007.

[4] G. Meneghesso, M. Meneghini, A. Tazzoli, N. Ronchi, A. Stocco, A. Chini and E. Zanoni, "Reliability Issues of Gallium Nitride High Electron Mobility Transistors", International Journal of Microwave and Wireless Technologies, 2(1), pp. 39-50, 2010.

[5] J. L Jimenez and U. Chowdhury, "X-Band GaN FET Reliability", International Reliability Physics Symposium, pp. 429 - 435, 2008.

[6] J. Joh and J. A. del Alamo, "Critical Voltage for Electrical Degradation of GaN High-Electron Mobility Transistors," IEEE Elec. Dev. Lett, Vol. 29, pp. 287-289, 2008.

[7] B. M. Paine, S. R. Polmanter, V. T. Ng, N. T. Kubota, and C. R. Ignacio, "Lifetesting GaN HEMTs with Multiple Degradation Mechanisms", unpublished.

[8] B. M. Paine, "Scaling DC lifetests to RF conditions", unpublished.

[9] D. Marcon, J. Viaene, P. Favia, H. Bender, X. Kang, S. Lenci, S. Stoffels, S. Decoutere, "Reliability of AlGaN/GaN HEMTs: Permanent leakage current increase and output current drop", Microelectronics Reliability vol. 52, pp. 2188-2193, 2012.

[10] B. M. Paine, C. R. Ignacio, and S. R. Polmanter, "DC Characterization of GaN HEMTs with Slow Traps", unpublished.

[11] B. M. Paine, T. Rust III, and E. A. Moore, "Measurement of Temperature in GaN HEMTs by Gate End-to-End Resistance", unpublished.

[12] M. Meneghini, N. Ronchi, A. Stocco, G. Meneghesso, U. K. Mishra, Y. Pei, and E. Zanoni, "Investigation of Trapping and Hot-Electron Effects in GaN HEMTs by Means of a Combined Electrooptical Method", IEEE Trans. Elec. Dev., vol. 58, pp. 2996 - 3002, 2011.

[13] S.Y. Park, C. Floresca, U. Chowdhury, J. L. Jimenez, C. Lee, E. Beam, P. Saunier, T. Balistreri, and M. J. Kim, "Physical degradation of GaN HEMT devices under high drain bias reliability testing", Microelectronics Reliability 49 (2009) 478-483.

[14] J. Joh, J. A. del Alamo, "RF Power Degradation of GaN High Electron Mobility Transistors", Proc. of the IEEE International Electron Devices Meeting, 20.2, 2010.

[15] P. Makaram, J. Joh, J. A. del Alamo, T. Palacios and C. V. Thompson, "Evolution of structural defects associated with electrical degradation in AlGaN/GaN high electron mobility transistors", Appl. Phys. Lett. vol. 96, 233509, 2010.

[16] G. I. Drandova, J. L. Jimenez, P. T. Goeller, A. P. Ferreira, "TriQuint's $2^{\text {nd }}$ Generation TQGAN25 Technology Reliability Assessment", Workshop on Reliability of Compound Semiconductors, pp. 95-97, 2013. 